\title{
Influence of Input Variables over the Wood Digestion in a Sulfite Pulp Mill for Biorefinery Purposes
}

\author{
Cristina Rueda \\ Dept. of Chemistry and Processes \& Resources Engineering (GER group) \\ C/ Gamazo 1, 39004, Santander, Spain \\ Tel: 34-942-201-359Ｅ-mail: ruedac@unican.es
}

Carlos Tejedor

Bosques 2000, Sniace S.A.

Crta. Ganzo s/n, 39300, Torrelavega, Spain

Tel: 34-942-835-421Ｅ-mail: bosques2000@ sniace.com

\begin{abstract}
Natalia Quijorna
Dept. of Chemistry and Processes \& Resources Engineering (GER group)

C/ Gamazo 1, 39004, Santander, Spain
\end{abstract}

Tel: 34-942-201-359Ｅ-mail: quijornan@unican.es

Ana Andrés

Dept. of Chemistry and Processes \& Resources Engineering (GER group)

Avda. los Castros s/n, 39005, Santander, Spain

Tel: 34-942-201-359_E-mail: andresa@unican.es

Alberto Coz (Corresponding author)

Dept. of Chemistry and Processes \& Resources Engineering (GER group)

C/ Gamazo 1, 39004, Santander, Spain

Tel: 34-942-201-359Ｅ-mail: coza@unican.es 
Received: June 6, 2015 Accepted: June 20, 2015

doi:10.5296/jbls.v6i2.8015

URL: http://dx.doi.org/10.5296/jbls.v6i2.8015

\begin{abstract}
Eucalyptus globulus is the most profitable specie in Europe for pulping. However, in recent years some diseases and pests have caused its defoliation, affecting the available quantity of wood. In this sense, the mills are studying how to avoid the loss of pulp yield as well as the optimization of byproducts in order to take advantage of every component present in the wood using biorefinery processes. One of the possible options is to complete the consumption of E. globulus with other species such as Eucalyptus nitens.

The objective of this paper is to study the behavior of both species related to the dissolving pulp manufacturing process as well as the characteristics of the resulting products. Parameters that can be very useful for the evaluation of the raw material, such as the growing data or density of both species, have been compared. Major attention has been focused on the composition of both species and how it affects the characteristics of the possible final products.

E. nitens presents good results of forestry characteristics, being better than E. globulus in terms of growing and resistance to frosts. The cellulose content of both species is similar, however the digestion process in the case of E. nitens needs to be improved in order to optimize the involved energy and the obtained products.
\end{abstract}

Keywords: Biorefinery, Eucalyptus, Globulus, Nitens, Pulp, Spent liquor, Sulfite process

\title{
1. Introduction
}

Forest fiber resources are the main materials to produce cellulose products and paper pulp. In recent years, half of the world's round wood harvest is used for industrial purposes (Willför et al., 2011). In addition, valorization options in pulping have been studied during the last decades because of the sugar and lignin content of wood, converting the pulp mills into the biorefinery concept (Rueda et al., 2015).

Eucalyptus is one of the genus most commonly used in Europe and specifically in the north of Spain to produce pulp because of its fiber size, quality and lighter color as well as its productivity and plasticity (Pérez Cruzado et al., 2011). It is the most profitable in Europe for this type of use, beating birch and other hardwoods.

Pulp manufacturers in northern Spain had traditionally used Eucalyptus globulus as raw material in their pulping processes to obtain dissolving pulp. However, in recent years some diseases, such as Mycosphaerella, and pests, such as Gonipterus scutellatus, have affected the quantity available of this wood (Otero et al., 2006; Sánchez et al., 2011). These pests and diseases cause massive defoliation in young leaves annually, producing important losses of growth and weakness of the masses, with generalized mortality in frost exposed zones (Tejedor, 2004a). 
In this way, some factories are studying how to palliate this situation. One option is the selection of the most resistant families and the cloning of the best trees of Eucalyptus globulus in order to get varieties tolerant to the diseases. Another option is to improve Eucalyptus nitens characteristics, such as wood density, growth, diseases resistance and coppice ability.

In this sense, the basic knowledge of the chemical composition and structure of the wood as raw material (Sixta, 2006) is fundamental to understand the pulping process and the possible valorization of the waste materials obtained in this process. Wood is formed mainly by cellulose, hemicellulose, lignin and small percentages of extractives and ash. In an acid sulfite process, the process in which this work is focused, the fraction of cellulose is oriented to obtain dissolving pulp; however, the rest of the components, lignin and hemicellulose, are byproducts that can be valorized into new high value-added products such as ethanol or xylitol from fermentable sugar (from the hemicellulose) and lignosulfonates (from the lignin) (Rueda et al., 2015).

The objective of this work is to study how far E. nitens affects the parameters of the existing process as well as the properties of the obtained pulp but also of the spent liquor for its valorization opportunities.

It is important to mention that the timber arriving to any factory is a quite heterogeneous material because many factors are involved in the wood quality: the genetic of the tree (not just the species, but also the provenance, the family, clones...) the soil of the forest, the age of the trunk, the position inside the trunk, etc. (Tejedor, 2004a). So, this Eucalyptus species can not be seen as a unique value applicable for E. nitens or E. globulus but a wide variety of values that can be found inside each species.

\section{Materials and Methods}

\subsection{Raw Materials}

The wood used has been Eucalyptus globulus and one selected tree of Eucalyptus nitens from Cantabrian forests supplied by Sniace SA group (Torrelavega, Spain). Logs have been chipped and classified. The chips used in the cooking experiments have 15-30 mm length and 2-4 mm thickness.

The parameters of the cooking liquor (made by dolomite, water and $\mathrm{SO}_{2}$ ) have to be as homogeneous as possible. In this work, the parameters have been the following: total $\mathrm{SO}_{2}$ (7.5-8.5g/100 mL liquor), combined $\mathrm{SO}_{2}(1.5-1.8 \mathrm{~g} / 100 \mathrm{~mL}$ liquor).

\subsection{Cooking Experiments}

The cooking experiments were carried out in one-liter stainless steel reactors with temperature and pressure control and an external electric heating system. For this, wood and fresh liquor were loaded into the digesters and after some operation conditions (pressure, $\mathrm{SO}_{2}$ content and residence time) unbleached pulp and spent liquor were obtained.

The process for each experiment has been the following: wood and cooking liquor are loaded 
into the digesters using a fixed liquid/solid ratio. Then, the reactors are pressurized using argon gas until 9 bar of pressure and the heating ramp until desired constant temperature is set. The digesters have an automatic system of pressure control which maintains the pressure constant throughout the whole process. After the desired time at maximum temperature, the heating is stopped and the pressure is relieved. Once atmospheric pressure is achieved, digesters are discharged. Finally, the composition of resulting spent liquor and pulp, if applicable, is analyzed.

\subsection{Analytical Methods}

The following methods were used for wood characterization. Tappi T257 (Tappi, 1993) was used to carry out the sample preparation. Extractives were determined according to the standard UNE EN ISO 14453 (ISO, 1999) for pulp, modified for its use with wood by means of an extraction with acetone as solvent using a soxhlet apparatus. Ash was measured using the standard Tappi T211 (Tappi, 1993) and a furnace at $525^{\circ} \mathrm{C}$. Lignin was determined by Tappi T222 (Tappi, 1993) as follows: carbohydrates in wood are hydrolyzed and solubilized by sulfuric acid; the acid-insoluble lignin is filtered off, dried, and weighed; the acid-soluble lignin can be determined in a solution after filtering off the insoluble lignin using a spectrophotometer based on absorption of ultraviolet radiation at $205 \mathrm{~nm}$. Holocellulose was determined with the Wise method (Wahab et al., 2013). The sample is treated with water and sodium chlorite in an acid medium achieved by the addition of some drops of acetic acid and it is heated using a water-bath at $75-80^{\circ} \mathrm{C}$. This procedure is repeated until the sample is bleached. In this case, it was carried out three times. After that, the sample is cooled, filtered and washed with water and acetone. Finally, the sample is dried and weighed. Cellulose in this work was determined as alpha-cellulose. Its content was measured using the standard Tappi T203 (Tappi, 1993) by means of which, the obtained material after the holocellulose determination is extracted consecutively with $17.5 \%$ and $9.45 \%$ sodium hydroxide solutions at $25^{\circ} \mathrm{C}$. The soluble fraction, consisting of beta- and gamma-celluloses, is determined volumetrically by oxidation with potassium dichromate, and the alpha-cellulose, as an insoluble fraction, is derived by difference.

The quality grade of cellulose pulp was evaluated by means of kappa index according to Tappi T236 standard (Tappi, 1993) and intrinsic viscosity following the guidelines of ISO/FDIS 5351 (ISO, 2009).

The spent liquor was characterized as follows. Free, total and combined $\mathrm{SO}_{2}$ were determined according to the titration method Tappi T604 (Tappi, 1993) with iodine and sodium hydroxide. Sugar content (glucose, xylose, arabinose, rhamnose and galactose), acids (acetic, levulinic and formic) and other decomposition products (furfural and hydroxymethyl furfural) were measured by a Shimadzu Prominence HPLC with SHODEX SH1011 column and Refraction Index detector according to Llano et al. (2013) method using $0.5 \mathrm{~mL} / \mathrm{min}$ of $0.005 \mathrm{M} \mathrm{H}_{2} \mathrm{SO}_{4}$ as a mobile phase, $60^{\circ} \mathrm{C}$ in the oven and 198 psi of column pressure.

\section{Results and Discussion}

Different characteristics of both species have been analyzed in order to study the possibilities 
of consuming both species in a pulp mill; starting with the forestry characteristics and followed by their density and chemical composition. Finally, the behavior in the chemical pulping has been assessed to improve the separation of the main components of the wood, giving the best valorization options of the spent liquor.

\subsection{Plantation}

Eucalyptus globulus is very sensitive to frosts, especially during the first two years, putting up with 5 and 30 frosts by year although in coastal areas this phenomenon is less frequent, but in higher altitudes these can present more than 70 times per year (Brinkmann, 1992). The most favorable temperature for the specie is situated as an annual average between 10 and $15^{\circ} \mathrm{C}$, with limits of $-4.5^{\circ}$ and $40.5^{\circ} \mathrm{C}$ for short periods of time (Brinkmann, 1992). This specie must not exceed seven dry months.

However, Eucalyptus nitens is able to bear the same temperatures and to grow enduring between 50 and 150 frosts per year. In comparison with E. globulus, previous studies (Tejedor, 2004a) have demonstrated that E. nitens, in general, is less affected by pests and diseases previously mentioned, especially in altitudes higher than 300 meters above sea level. There are also important differences between provenances of $E$. nitens for diseases resistance.

Additionally, the growing data of both species for the region of Cantabria, 24-29 $\mathrm{m}^{3} / \mathrm{ha} / \mathrm{year}$ for E. nitens and 13-17 $\mathrm{m}^{3} / \mathrm{ha} /$ year for E. globulus (Forest Patrimony of Sniace group), gives an idea of how the productivity in the whole process from the forest to the factory can increase. Therefore, E. nitens presents better forestry characteristics according to the purpose of this work.

\subsection{Density}

Density is one of the most important properties of wood and pulping processes because it is related to mechanical resistance and to cellulosic and energetic flair. Optimal density is a function of end-use of wood.

Table 1 shows the density values obtained by other authors and those of this work. First, what attracts attention is that the density of Eucalyptus nitens is slightly lower than Eucalyptus globulus. In Cantabrian forest, the results are $475-650 \mathrm{Kg} / \mathrm{m}^{3}$ for adult trees of E. globulus and $460-520 \mathrm{Kg} / \mathrm{m}^{3}$ for E. nitens. E. globulus presents more density than E. nitens in all cases; however, the studied interval of variation is wider in the case of E. globulus. Density is a parameter which is very dependent on other factors such as the genetic of the tree (provenance, family, clone...), the age of trunk, the position inside the trunk and the forest location. 
Table 1. E. globulus and E. nitens density values $\left(\mathrm{Kg} / \mathrm{m}^{3}\right)$

\begin{tabular}{|c|c|c|}
\hline & E. globulus & E. nitens \\
\hline Cotterill (1997) & 533 & 463 \\
\hline Evans (2000) & - & 471.1 \\
\hline Monteoliva (2002) & 549 & - \\
\hline Paz (2003) & 554.5 & 499 \\
\hline This work & 532 & 485 \\
\hline
\end{tabular}

\subsection{Composition}

Composition knowledge is very important to evaluate the wood for pulping and valorization options. Between hardwoods and softwoods, generally the first kind has a higher proportion of holocellulose and less lignin although a greater percentage of extractives. However, among different species of hardwoods there are differences that make them suitable or non-suitable for a fixed pulping process. For dissolving pulp, higher contents of cellulose and lower of lignin are more interesting. Thus, the results obtained by different authors and those of this work are shown in tables 2 and 3.

Table 2. E. globulus composition values (\%)

\begin{tabular}{|c|c|c|c|c|c|}
\hline & Alonso (1976) & Pereira (1988) & Cotterill (1997) & Paz (2003) & This work \\
\hline Extractives* & $0.42 / 1.4$ & 4.9 & - & 1.18 & 1.5 \\
\hline Ash & 0.48 & 0.40 & - & - & 0.35 \\
\hline Lignin & 21.24 & 23.1 & 27 & 20.85 & 23.28 \\
\hline Alpha-cellulose & - & $54^{* *}$ & 45 & 50.65 & 51.3 \\
\hline Holocellulose & 79.47 & - & - & 84.1 & 80.5 \\
\hline
\end{tabular}

* Different solvents employed by each author

** Total content of cellulose

Table 3. E. nitens composition values (\%)

\begin{tabular}{|c|c|c|c|c|}
\hline & Alonso (1976) & Cotterill (1997) & Paz (2003) & This work \\
\hline Extractives* & $0.31 / 0.76$ & - & 1.57 & 1.98 \\
\hline Ash & 0.24 & - & - & 0.31 \\
\hline Lignin & 21.33 & 27 & 21.41 & 25.43 \\
\hline Alpha-Cellulose & - & 43 & 47.33 & 51.2 \\
\hline Holocellulose & 83.14 & - & 83.27 & 78.4 \\
\hline
\end{tabular}

* Different solvents employed by each author

The first parameter in both tables is related to the percentage of extractives, which has very different values due to the use of different solvents such as acetone (this work), ethanol (Paz, 2003), ether (Alonso, 1976), ethanol-benzene (Alonso, 1976) or a mixture of dichloromethane, ethanol and water (Esteves, 2008; Pereira, 1988).

The second parameter is ash. Very similar results have been obtained for both species. 
According to other parameters such as alpha-cellulose, it can be said that E. nitens, which presents similar values to $E$. globulus, theoretically looks suitable at the same level as $E$. globulus in order to obtain pulp. Regarding lignin, its slightly higher content in the case of $E$. nitens can make the process a little more complicated; however, this content can increase the valorization options of the byproducts oriented to a biorefinery.

\subsection{Pulping}

In order to evaluate the suitability of both species to produce pulp and the development of valorization options, an analysis of the cooking stage has been done in two steps: the study of the impregnation step and the study of the behavior of both species in pulping.

\subsubsection{Impregnation Step}

The non-uniformity of pulp has unfavorable effects on the cooking and bleaching steps. To obtain a uniform pulp, the cooking liquor must be equally distributed into wood chips, that is, to achieve a uniformly impregnated wood in the minor possible time (Gullichsen and Sundqvist, 1995; Gustafsson, 1988). This is why the impregnation step has an important role in the whole process because it is the first and can have a bearing on the improvement of the delignification and penetration times of liquor into wood. The effect of the quality of the impregnation has been studied by other authors (Gullischen et al., 1995; Hart et al., 2011; Kazi et al., 1998; Malkov et al., 2004).

Some impregnation trials were carried out at laboratory scale. The impregnation value in each trial is obtained taking into account the difference of liquor volume among the input and the output, and using an average value of liquor density of $1054 \mathrm{~kg} / \mathrm{m}^{3}$ obtained in a previous work (Rueda et al., 2015). Therefore, the final impregnation value is given in $\mathrm{mg} / \mathrm{g}$ dried matter (DM).

Once the impregnation is obtained in $\mathrm{mg} / \mathrm{g}$, the percentage of impregnation can be calculated in every period of time taking into account the impregnation at that time and the maximum value that the wood can be impregnated for each specie (showed in table 4). Based on the experience of the mill, an $80 \%$ of impregnation is considered to be enough in this type of process.

In order to obtain a representative curve of the impregnation, data were represented by first order exponential equations according to equation 1; where $y$ represents impregnation in $\mathrm{mg} / \mathrm{gDM}$ and $a, b$ are constants. The obtained parameters are shown in table 4 and the curves in figure 1 .

$$
y=a\left(1-e^{(-b x)}\right)
$$

Table 4. Obtained parameters for both types of wood

\begin{tabular}{|c|c|c|}
\hline & E. globulus & E. nitens \\
\hline $\mathrm{a}(\mathrm{mg} / \mathrm{gDM})$ & 558.56 & 764.68 \\
\hline $\mathrm{b}\left(\mathrm{min}^{-1}\right)$ & 0.01292 & 0.009350 \\
\hline
\end{tabular}




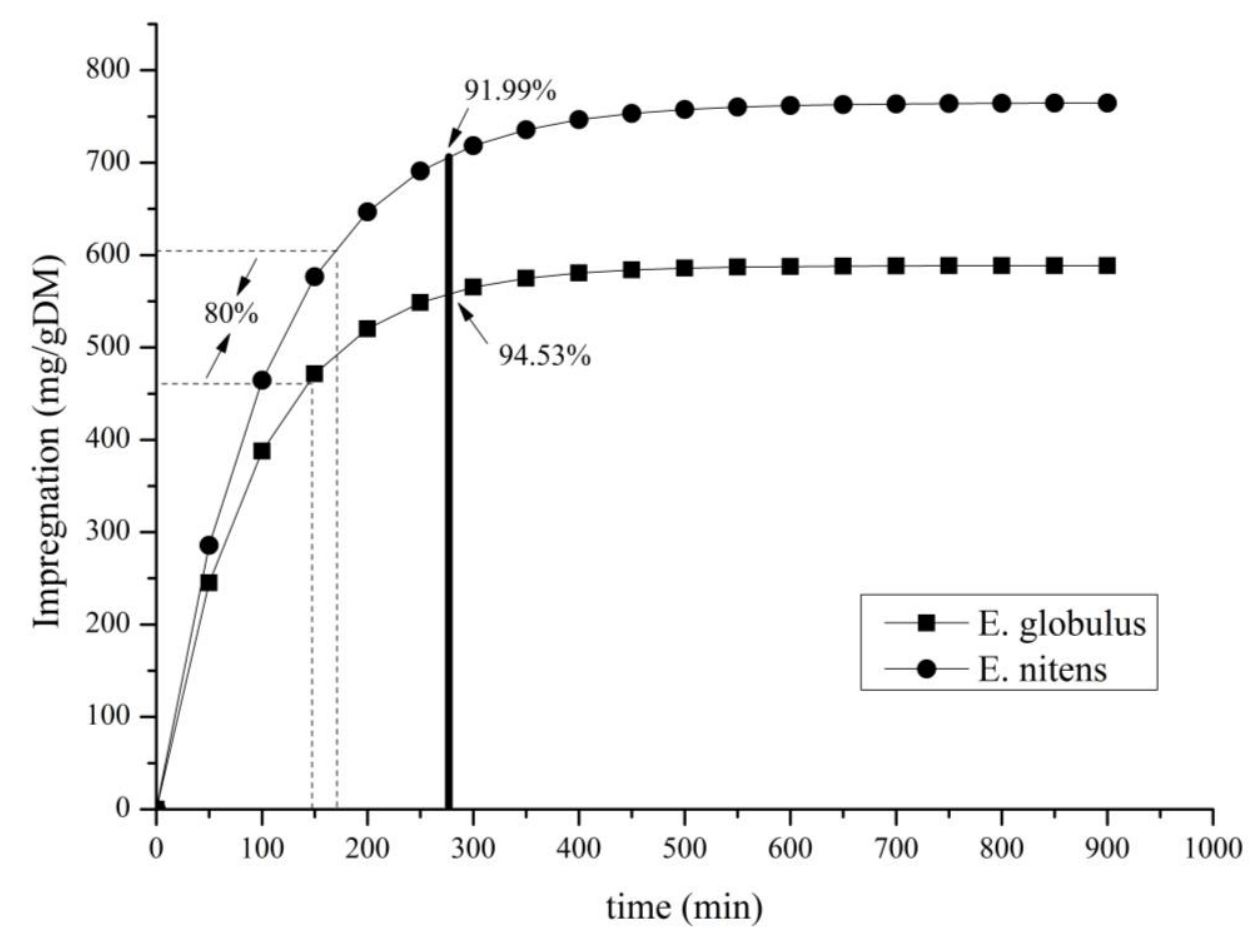

Figure 1. Tendency of impregnation stage of E. globulus and E. nitens, in mg/gDM and in impregnation percentage.

As can be seen in table 4 and figure 1, E. nitens has a higher maximum impregnation value, which means that for the same conditions at certain time, it will impregnate more milligrams per grams of available dry wood; however, it will be less impregnated than E. globulus because it needs more time to reach the same percentage of impregnation. Furthermore, both types of wood fulfill the requirement of an impregnation of $80 \%$. Focusing on time employed in the existing mill, the impregnation obtained for Eucalyptus globulus represents a $94.53 \%$ of the available wood versus $91.99 \%$ for Eucalyptus nitens. Both values exceed the $80 \%$ declared as enough, therefore E. nitens could be used without big modifications in the existing process.

\subsubsection{Cooking Step}

A literature search was carried out focusing on the pulping behavior of these two types of wood in different processes. The aim is to evaluate the yields and the properties of both in pulp and byproducts, to get better products and higher valorization opportunities.

All the literature consulted refers to alkaline processes and not to sulfite processes. On one hand, the study of Paz (Paz, 2003) shows that Eucalyptus globulus ( 54\%) has a little more yield than Eucalyptus nitens $(\sim 52.7 \%)$ for a final kappa closest to $14 \pm 1$. Escalona et al. (Escalona et al., 2000) affirms that E. globulus has the best pulping yield and furthermore, $E$. nitens consumes more energy in cooking to reach a similar grade of delignification (kappa $16 \pm 1$ ). On the other hand, Clarke (Clarke, 2000) affirms that the yields of the samples that are used in his work are compared favorably to those reported for Eucalyptus globulus. 
In order to check some of the statements of the literature, some laboratory tests have been carried out and the properties of the resultant products after the cooking process have been analyzed.

The experiments were carried out as was mentioned in the epigraph 2.2., fixing the liquid/solid ratio at $20: 1 \mathrm{~L} / \mathrm{Kg}$ in order to avoid the diffusion and to study only the effect of the cooking stage, as the impregnation stage was previously studied.

Figure 2 shows the evolution of lignosulfonates and total monomer content of spent sulfite liquor of E. nitens and E. globulus digestion. The E. nitens showed a higher delignification grade since a higher content of lignosulfonates was found in the spent sulfite liquor. Furthermore, the total sugar content is slightly lower in the spent liquor obtained using $E$. nitens than in the one obtained by E. globulus digestion. This indicates that E. nitens spent liquor would reach a greater degree, better for lignosulfonate valorization purposes than sugars.
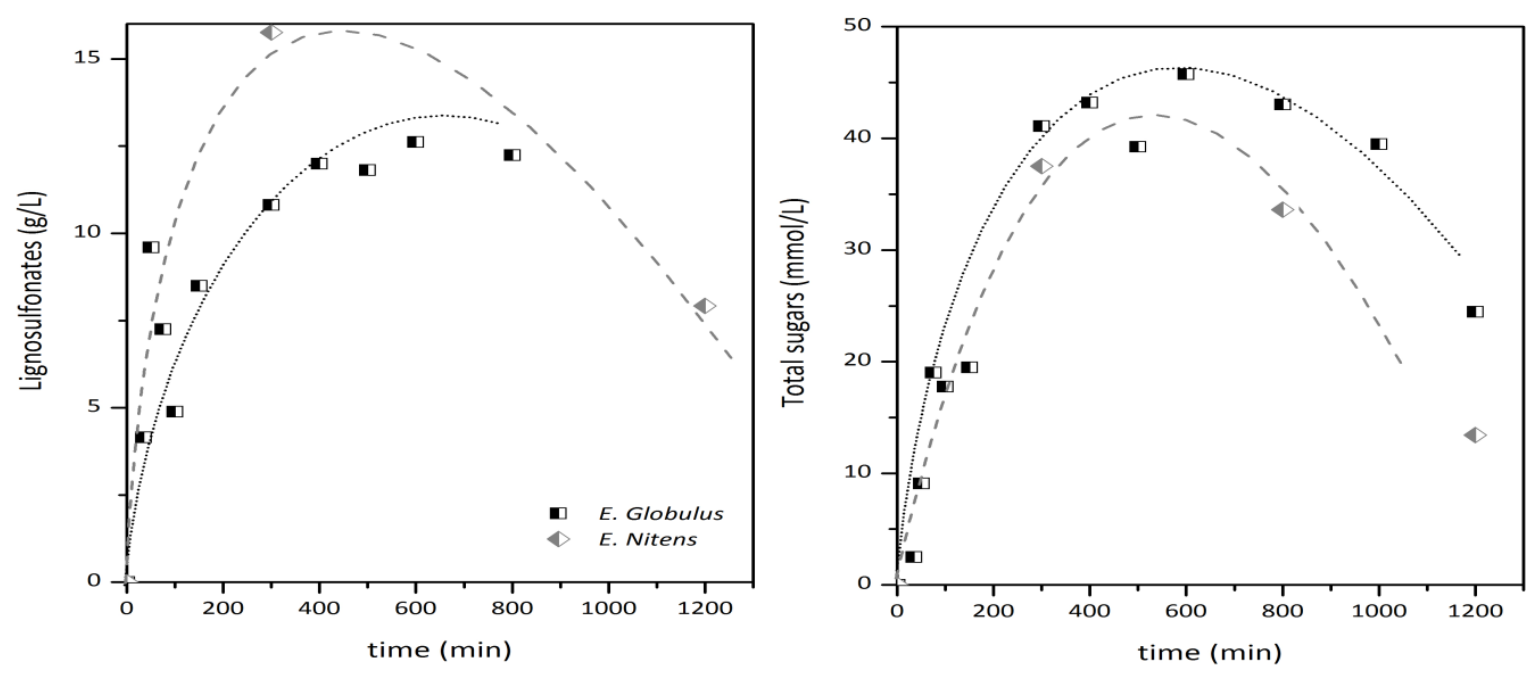

Figure 2. Evolution of lignosulfonates and total sugar content in spent sulfite liquor with time for E. globulus and E. nitens digestion.

Taking a cooking time of 300 minutes, the properties of the obtained pulp have been determined and shown in table 5.

Table 5. Kappa number and viscosity for different samples

\begin{tabular}{|c|cc|cc|}
\hline \multirow{2}{*}{ TIME (min) } & \multicolumn{2}{|c|}{ Kappa } & \multicolumn{2}{c|}{ Viscosity $(\mathrm{mL} / \mathrm{g})$} \\
\cline { 2 - 5 } & E. globulus & E. nitens & E. globulus & E. nitens \\
\hline 300 & 7.57 & 10.87 & 578.19 & 374.40 \\
\hline
\end{tabular}

Regarding to the pulp properties, it seems that the digestion process in the case of E. nitens is more aggressive and it is able to isolate the lignin and hemicellulose from cellulose; however, the degradation of sugar could be too accused, turning their transformation into other decomposition products such as furfural or hydroxymethyl furfural (HMF) in the spent liquor. This means that the process could be carried out at a lower temperature which involves an 
important decrease of the energy costs.

Based on the obtained results and the biorefinery purposes, E. nitens shows better results in terms of lignin valorization; however, the optimization of the pulping process using nitens is needed in order to increase the hemicellulosic content in the hydrolyzate (spent liquor).

\section{Conclusions}

Eucalyptus globulus commonly used in northern Spain and the Iberian peninsula to produce pulp, has been afflicted in recent years by some pests and diseases that affect the available quantity of this wood. The evaluation as a raw material in the sulfite pulping process of other species such as Eucaliptus nitens has been analyzed in this work.

In terms of forestry characteristics, E. nitens is less affected by pests and diseases and also less sensitive to frosts. Furthermore, it has higher growing data. Another important characteristic is the wood density which in the studied case is lower for E. nitens. However, E. nitens can make a difference with higher growth and occupying areas where E. globulus does not withstand; which means that it could be planted successfully in these areas.

Regarding the chemical composition of both species, E. nitens presented in the studied case a higher content of lignin and similar content of alpha-cellulose than E. globulus, which theoretically would mean that $E$. nitens is a good candidate for producing dissolving pulp and furthermore, it would produce more byproducts, valid for biorefinery purposes. To verify this, some laboratory tests were carried out showing that in the first part of the process, the impregnation step, E. nitens needs a bit more time to reach the desired impregnation of the wood. However, in the second step of the process, the cooking stage, E. nitens gives a higher concentration of lignin in the spent liquor with only a little decrease in the sugar content and worse results of the quality parameters in the dissolving pulp. A decrease of the temperature of the digestion is recommended in this case in order to improve the properties of pulp and decrease other decomposition products in the hemicellulose fraction of the spent liquor, giving more productivity in the process.

To conclude, it can be said that E. nitens can be used to produce dissolving pulp and other byproducts which can be valorized by means of different biorefinery processes. However, an optimization of the pulping process should be carried out.

\section{Acknowledgement}

The authors gratefully acknowledge the financial support for this research by the KBBE-2012-6-311935 research project under the European Union Seventh Framework Programme. www.brigit-project.eu.

\section{References}

Alonso Aguilar L. (1976). Análisis químico de maderas de diferentes especies forestales. Instituto Nacional de Investigación y Tecnología Agraria y Alimentaria (INIA). Gobierno de España.

Brinkman, F. (1992). Estudio de mercado y análisis económico de plantaciones de eucalipto. 
Proyecto de Título Ing. Agrónomo, Pontificia Universidad Católica de Chile.

Clarke C.R.E. (2000). Wood and pulp properties of four New South Wales provenances of Eucalyptus nitens grown on a warm and a cold site in South Africa. Appita Journal, 53(3), 231-236.

Cotterill P., \& Macrae S. (1997). Improving Eucalyptus pulp and paper quality using genetic selection and good organization. Tappi Journal., 80(6), 82-89

Escalona J., González R., \& Millar H. (2000). Evaluación de especies de Eucalyptus. Celulosa y papel (Chile), 205-215

Esteves B., Graça J., \& Pereira H. (2008). Extractive composition and summative chemical analysis of thermally treated eucalypt Wood. Holzforschung, 62, 344-351. http://dx.doi.org/10.1515/HF.2008.057

Evans R., Stringer S., \& Kibblewhite R. P. (2000). Variation of microfibril angle, density and fibre orientationin twenty-nine Eucalyptus nitens trees. Appita Journal, 53(5), 450-457

Gustafsson, R. R., Jimenez, G., McKean, W., \& Chian, D. S., (1988). The role of penetration and diffusion in pulping non-uniformity of softwood chips. Proceedings of the 1988 Pulping Conference. 685-691

Gullichsen, J. \& Sundqvist, H. (1995). On the importance of impregnation and chip dimensions on the homogeneity of kraft pulping. Proceedings of the Pulping Conference, Chicago, 227 - 234.

Hart, P., Colson, G. W., Antonsson, S., \& Hjort, A. (2011). Impact of impregnation on high kappa number hardwood pulps. BioResources, 6(4), 5139-5150.

ISO, ISO/FDIS 5351 International Standard (2009). Pulps - determination of limiting viscosity number in cupry-ethylenediamine (CED) solution.

Kazi, K. M. F., Jollez, P., \& Chornet, E. (1998). Preimpregnation: an important step for biomass refining processes. Biomass and Bioenergy, 15(2), 125-141. http://dx.doi.org/10.1016/S0961-9534(98)00008-7

Llano T., Quijorna N., Portilla A.I., Andrés A., Coz A. (2013). Analysis of sugars, intermediates and inhibitors in sulphite pulping by HPLC/RID. XXII Tecnicelpa-International Forest Pulp and Paper Conference. October 2-4. Tomar (Portugal).

Malkov, S., Leavitt, A., \& Stromberg, B. (2004). Improved Understanding of Chip Steaming and Impregnation. In 2004 Engineering, Pulping, and PCE\&I Conference.

Monteoliva S., Nuñez C., Igartúa D. (2002). Densidad básica, longitud de fibras y composición química de la madera de una plantación de Eucalyptus globulus en la provincia de Buenos Aires, Argentina. Proceedings Iberoamerican Congress on pulp and paper research 2002 (CIADICYP)

Otero L., Aguín O., Mansilla J.P, Montenegro D., Pintos C. (2006). Identificación de especies de Mycosphaerella en Eucalyptus globulus y E. nitens en Galicia. Proceedings of the Thirteenth National Symposium of the Spanish Society of Plant Pathology. Murcia, Spain

Paz J. (2003). Características físicas, químicas y biométricas de distintas especies de Eucalyptus y su actitud pulpable. Acta Simposio Los Eucalyptus en el desarrollo forestal de Chile. Pucón, Chile. 537- 561 
Pereira H. (1988). Variability in the Chemical Composition of Plantation Eucalypts (Eucalyptus Globulus Labill.). Wood and Fiber Science, 20(1), 82-90.

Pérez-Cruzado C., Merino A. \& Rodríguez-Soalleiro R. (2011). A management tool for estimating bioenergy production and carbon sequestration in Eucalyptus globulus and Eucalyptus nitens grown as short rotation woody crops in north-west Spain. Biomass and Bioenergy, 35, 2839-2851.

Rueda C., Calvo P. A., Moncalian G., Ruiz G., \& Coz A. (2015). Biorefinery options to valorize the spent liquor from sulfite pulping. Journal of Chemical Technology and Biotechnology. (wileyonlinelibrary.com), in press, DOI 10.1002/jctb.4536.

Sánchez Márquez S., Bills G. F., Zabalgogeazcoa I. (2011). Fungal species diversity in juvenile and adult leaves of Eucalyptus globulus from plantations affected by Mycosphaerella leaf disease. Annals of Applied Biology, 158, 177-187. http://dx.doi.org/10.1111/j.1744-7348.2010.00449.x

Sixta H. (2006). Handbook of pulp Vol. I. Wiley-Vch. http://dx.doi.org/10.1111/j.1744-7348.2010.00449.x

Smook GA. (2002). Handbook for Pulp \& Paper Technologists, Angus Wilde Publications Inc.

TAPPI Standard Test Methods (1993). Fibrous Materials and Pulp Testing T1-200 Series.

Tejedor C. (2004a). "Basic density selection for Eucalyptus globulus in northern Spain. Within-tree and between-tree variation." In "Eucalyptus in a changing world" pg. 690-691. Proc. IUFRO Conf., Aveiro (Portugal).

Tejedor, C. (2004b). "Integral management of Mycosphaerella leaf disease in northern Spain" In "Eucalyptus in a changing world" pg. 614-621. Proc. IUFRO Conf., Aveiro (Portugal).

Wahab, R., Mustafa, M. T., Salam, M. A., Sudin, M., Samsi, H. W., \& Rasat, M. S. M. (2013). Chemical composition of four cultivated tropical bamboo in genus Gigantochloa. Journal of Agricultural Science, 5(8), p66. http://dx.doi.org/10.5539/jas.v5n8p66

Willför et al. (2011). Raw materials. In Fardim P. (Ed.), Chemical Pulping Part 1, Fibre Chemistry and Technology (pp. 16-186). Paper Engineers' Association/Paperi ja Puu Oy.

\section{Copyright Disclaimer}

Copyright for this article is retained by the author(s), with first publication rights granted to the journal.

This is an open-access article distributed under the terms and conditions of the Creative Commons Attribution license (http://creativecommons.org/licenses/by/3.0/). 